\title{
LA EDUCACIÓN POPULAR DESDE LA OPINIÓN DE LA PRENSA OBRERA EN CHILE (1903-1927)
}

\author{
POPULAR EDUCATION FROM THE OPINION OF THE \\ WORKERS PRESS IN CHILE (1903-1927)
}

\author{
Jaime González González \\ Dr. en Antropología \\ Universidad Autónoma de Chile \\ jaime.gonzalez@uautonoma.cl \\ Geraldine Sandoval Dotte \\ Magister en Historia \\ Centro de Educación y Cultura Americana (CECA) \\ geraldine@cecamericana.cl
}

Resumen: El presente artículo analiza la opinión de la prensa obrera sobre la educación popular en el período 1903-1927. El trabajo se nutre de un corpus de periódicos sistematizados por dos tesis de grado en historia. Los principales resultados dan cuenta de distinciones marcadas de opinión entre la prensa anarquista y los periódicos de corte socialista. Las principales diferencias se observan en el terreno de la educación de la mujer, donde resulta evidente una propuesta rupturista de los periódicos ácratas en torno a su papel en la sociedad. La investigación concluye que los medios presentan una serie de semejanzas, tanto en el modelo de prensa al que tributan, como en su preocupación por el mundo popular en general. El estudio también concluye que los principales disensos se observan en el plano doctrinal, a la hora de discutir sobre la educación que debe recibir la mujer popular.

Palabras clave: educación popular, opinión, prensa obrera.

Abstract: This article analyzes the opinion of the working press about popular education in the period 1903-1927. The work is nourished by a corpus of newspapers systematized by two theses of degree in history. The main results show marked distinctions of opinion between the anarchist press and socialist newspapers. The main differences are observed in the field of women's education, where a rupturist proposal of the anarchic newspapers about their role in society is evident. The investigation concludes that the media present a series of similarities, both in the press model to which they pay tribute, and in their concern for the popular world in general. The study also concludes that the main disagreements are observed at the doctrinal level, when discussing the education that popular women should receive.

Key words: popular education, opinion, working press. 


\section{INTRODUCCIÓN}

La historiografía sobre la educación en Chile se caracteriza por su diversidad y amplitud. De esta discusión destacan posturas que vinculan la escuela pública con el temor político al socialismo (Illanes, 1990). Desde esta perspectiva, la escuela surgiría como uno de los pilares de la emergencia de un nuevo orden social integrativo, donde el statu quo es cuestionado con un llamado a incorporar al pueblo y sobre todo a los hijos del proletariado. La hipótesis central de esta perspectiva sostiene que la emergencia de la escuela constituiría una de las recientes claves para la refundación de nuevas relaciones sociales a través de la cultura escolar. Desde la misma perspectiva, el temor a la masa bárbara, que ejercía acciones transgresoras desde la perspectiva de la élite -tales como el bandidaje-generó la necesidad de crear iniciativas educativas privadas como método de control más eficiente que la represión (Salazar, 1989).

Siguiendo la misma línea, existen posturas bibliográficas que plantean que la ausencia del Estado y la ineficacia y poca amplitud del sistema educativo público llevó a las élites a crear iniciativas privadas que tuvieron como principal función la homogeneización de la población y la búsqueda de la estabilidad social en el contexto de las revueltas generadas por el movimiento obrero, traduciendo, de esta forma, su ideario político o religioso en la práctica pedagógica (Reyes, 2005).

Por un rumbo diferente se observan formulaciones que rescatan el papel de entidades privadas en el proceso de escolarización nacional (Aedo-Richmond, 2000). En este tipo de análisis, se describe la trayectoria de educandos y docentes en el contexto de la ampliación de la cobertura escolar primaria (Egaña, 2003). Por este mismo camino se consideran proposiciones más complejas, que definen la escuela como un espacio social donde lo privado y lo público se vinculan y confrontan (Egaña y Monsalve, 2006). Esta perspectiva centra el análisis en situaciones inclusivas o conflictivas para cada sujeto, donde la relación de dominio de lo público sería la justificación de su condición de ente socializador (Egaña y Monsalve, 2006).

Otras propuestas centran el análisis en la figura de los docentes (Núñez, 2003), defendiendo como hipótesis que -independientemente de las posturas individuales tradicionalistas- los profesores como cuerpo jugaron un papel promotor del cambio educacional. Dentro de este mismo marco, se sostiene que los maestros contribuyeron a la introducción de formas de organización educacional de carácter democrático.

Una perspectiva diferente se observa en la obra de Jorge Barría (1971), quien vincula la educación obrera con las condiciones objetivas y subjetivas de esta clase social. De esta manera, los procesos de proletarización, sumados a la formación de la Sociedad de la Igualdad y las Sociedades de Socorro Mutuo, fueron perfilando la conformación del proceso educativo de este grupo social. En esta contingencia, los partidos fueron activos actores de la educación popular, destacando entidades como el Partido Demócrata y, posteriormente, el Partido Obrero Socialista (POS). Este último partido, a partir de los hechos de 1917, se integraría a la Tercera Internacional, dando nacimiento al Partido Comunista de Chile. De esta manera, los partidos fueron generando históricamente una política educacional que 
partió desde la búsqueda de beneficios para la población obrera, hasta la educación militante y de clase del proletariado. Con base en esta última perspectiva, el Partido Comunista defendió un sistema de educación integral, que dejara de reproducir la estructura social de la época.

Por una ruta semejante se observan perspectivas que centran el análisis tanto en las iniciativas de educación popular surgidas desde las élites, como de las mismas clases populares (Salazar, 1987; Reyes, 2005). Desde esta lectura, se sostiene que en los grupos dominantes existió una idea transversal al crisol político -con claros matices de posturas liberales y conservadoras- que debía establecerse una instrucción de estas características. El objetivo de ella era homogeneizar a la población, controlando parcialmente los movimientos sociales expresados principalmente en el Movimiento Obrero (Reyes, 2005). En el caso de los grupos populares, los inicios de su educación se asocian a la iniciativa estatal, cuya intención, si bien inicialmente fue romper con el pasado colonial, terminó por reproducir la estructura social previa a la emancipación (Salazar, 1987).

Una perspectiva diferente observamos en la obra de Sol Serrano (2012). La investigadora sostiene que el sistema escolar del período constituyó una exitosa tarea política y cultural, debido a que conformó un agente democratizador de la sociedad chilena. Su hipótesis considera desde aspectos ideológicos, hasta dimensiones sociológicas y políticas sobre este hecho. El sistema escolar del período logró desarrollar una democracia social, más una sustancial mejora en el aprendizaje de los educandos y una mayor institucionalización de la escuela. A esto se sumó el ingreso de nuevos actores letrados con agendas propias al espacio público -obreros, mapuches, mujeres y profesores-, independientemente de que el sistema escolar no lograra modificar la estructura social. Para el caso del proletariado, destaca la presencia de una élite intelectual obrera, la adquisición de un carácter de clase predominantemente ilustrada, más una concepción de la educación como instrumento emancipador. Desde esta perspectiva, la autoeducación popular -valiéndose de diversas plataformas, tales como la prensa, conferencias, representaciones teatrales y veladas-condujo a un amplio proyecto de ilustración obrera, que defendería el progreso moral e intelectual del trabajador como propaganda política.

Una última ruta crítica se observa en el debate generado en el extremo norte de Chile. En este campo analítico, los estudios sobre el objeto se caracterizan por estar cruzados por la discusión en torno al proceso de chilenización (Van Kessel, 1992; González, 2002; Castro, 2004). En este sentido, las investigaciones sobre escolarización se vinculan con el proceso de nacionalización estatal de la región nortina, debate que refleja tres grandes orientaciones. La primera vincula la educación pública con la desarticulación cultural de poblaciones indígenas, específicamente la aymara (Van Kessel, 1992). La segunda perspectiva sostiene que -sin desestimar el papel hegemónico de la educación pública sobre la población- la escuela fiscal generó un proceso bidireccional, siendo esta entidad resultado de una relación interactiva entre el Estado chileno y las comunidades andinas (González, 2002).

Una tercera visión se observa en la obra de Carolina Figueroa y Benjamín Silva (2006), perspectiva que sostiene que, debido a las condiciones materiales y políticas de las 
escuelas de la época, el proceso de chilenización tuvo menos efectividad que la esperada. Siguiendo esta orientación, la relativa ausencia del Estado en la región y el predominio de escuelas privadas (Figueroa, Silva, 2006; Silva, 2010), además de las insolvencias materiales y de infraestructura que enfrentaron los propios educadores -sin mencionar su respectiva renta y la ausencia escolar en planteles públicos-, generaron serias limitaciones al mencionado proceso (Silva Figueroa 2011; Silva, 2009, 2010 y 2013).

El debate presentado constituye un relevante aporte para la historia social de la educación en Chile. La diversidad teórica y metodológica que ofrece este estado de la cuestión, permite entender el problema desde las múltiples dimensiones del objeto. No obstante, se nos presenta una dimensión problemática ligada a la presencia de otros agentes que incidan en el terreno educativo. Este ámbito está ligado a la prensa escrita y su acción ideológica en torno a esta materia. De este problema tratará el siguiente apartado.

\section{EL PROBLEMA}

Un aspecto problemático a la hora de estudiar la historia social de la educación en Chile, es cuando esta se pretende abordar desde la prensa escrita. En esta materia, se observan perspectivas diferentes desde la historia y otras ciencias sociales, producto de la lectura teórica y metodológica ocupada para la aproximación a estas tanto en calidad de fuentes, como en calidad de objeto de estudio. De esta manera, el estado del arte en torno a esta en Chile, oscila desde los estudios propiamente descriptivos (Valdebenito, 1956; Silva Castro, 1958; Peñafiel Peña, 1994), hasta análisis explicativos sobre el fenómeno (Arias, 1970; Moulián, 1987; Santa Cruz, 1988 y 1996; Ossandón, 1996; González, 2002).

Independiente de las diferencias de aproximación en esta literatura, la discusión coincide que los medios de comunicación fundan su opinión tanto en la ideología en que se inspiran, como en el espacio en que publicitan su mensaje. En este sentido, el lugar en donde se emite la opinión cumple un papel de importancia a considerar.

En este terreno, la investigación nos ofrece dos caminos metodológicos diferentes a seguir: 1) abordar los periódicos de época en calidad de fuentes primarias; 2) aproximarse a la prensa en calidad de objeto de indagación. En este artículo los periódicos serán abordados en calidad de objeto de estudio. En este sentido, la prensa será entendida como agentes sociales y políticos generadores de opinión en tópicos fundamentales del debate ideológico nacional. De esta manera, este artículo estudiará la opinión de la prensa obrera de este período, con el fin de analizar su postura en torno a la educación del mundo popular chileno. Para ello se contemplan una serie de periódicos de la época, más un plan de análisis, materia que tratarán las siguientes líneas.

\section{METODOLOGÍA}

El presente artículo trabaja con un corpus de columnas de los periódicos obreros Mar y Tierra, La Hoja Popular, El Socialista, Verba Roja, El Martillo de Antofagasta, La Defensa Obrera y El Despertar de los Trabajadores sistematizadas en tres tesis de grado en 
historia ${ }^{1}$. Si bien estos materiales son ocupados como fuentes para la investigación, el acercamiento metodológico a estos es desde el entendimiento de la prensa en calidad de objeto de estudio. En este sentido, el abordaje de los textos escritos de los medios se realiza más desde el terreno de la opinión que generan los periódicos, que desde el plano de la información o "noticia" que estos pudieran proporcionar.

En el terreno del plan del análisis, la investigación se funda en los modelos teóricos formulados tanto en la obra de Jürgen Habermas (1981), como en el trabajo de Carlos Ossandón (1996). De esta manera, la lectura de las fuentes periodísticas se realizará desde la idea de opinión pública, entendida como dimensión social intermedia entre la producción económica y la acción política, donde ésta destaca en calidad de vida social pública (Habermas, 1981). A esta estrategia se sumará la propuesta tipológica sobre modelos de periódicos, ligada a la dicotomía conceptual entre modelo doctrinario y modelo informativo de prensa (Ossandón, 1996). En este sentido, los periódicos sistematizados serán entendidos como medios de comunicación, cuya opinión dependerá del tipo de prensa a la que tributa. Sobre esta base, dispondremos de un procedimiento que permitirá identificar y caracterizar los medios seleccionados, así como también del método para interpretar los discursos emitidos por esta prensa. Las siguientes líneas tratarán una serie de opiniones de prensa en torno a la educación del mundo obrero, la educación de la mujer y la educación de la infancia en Chile.

\section{RESULTADOS Y ANÁLISIS}

\section{La educación al mundo obrero}

La prensa obrera partidaria de la educación popular en este período defiende su propuesta educativa desde una serie de declaraciones de principios. Estos principios están ligados tanto a la condición social de los trabajadores, como a sus adversarios ligados a los grupos dominantes. En este terreno, el periódico Mar y Tierra sostiene:

"Al pensar y discutir, el abismo de ignorancia en que está sumida la mentalidad del trabajadores del mar, que troncha es flor las esperanzas de un lejítimo bienestar, conquistado en las luchas del trabajo, nos ha inducido a publicar este periódico en defensa y amparo del derecho de los trabajadores del mar." Mar y Tierra, 12 de Marzo 1911:1. En (Brión, 2016)

Por un rumbo semejante se observa la declaración de principios de La Hoja Popular, que sostiene:

"Queremos referirnos a uno solo: a la sinceridad i a la verdad de las informaciones destinadas a ilustrar i a formar conciencia de la gran masa del público, llegando a

\footnotetext{
${ }^{1}$ Nos referimos al trabajo de Geraldine Sandoval titulado "La emancipación del pueblo depende de la educación. El Despertar de los Trabajadores como expresión de los ideales educativos del Movimiento Obrero. Iquique, 1912-1926", de Natasha Palma y Franco Pinto titulado "Educación anarquista en Chile. Propuestas y críticas educativas libertarias desde su prensa, 1903-1927" y a la tesis de Catalina Brión titulada "illumina tu razón en el estudio para la lucha social"! Demandas, ideales y propuestas educativas del movimiento obrero en Valparaíso, 1910-1920." Para profundizar en esto ver (Sandoval, 2012; Palma y Pinto, 2015; Brión, 2016).
} 
ejercer una influencia tan efectiva que con justicia se ha llamado a la prensa el "cuarto poder del Estado" La Hoja Popular, Junio 1912. №10: 3. En (Brión, 2016)

Así mismo, El Despertar de los Trabajadores, hace referencia a la importancia de la educación popular y a la despreocupación mostrada por las élites y el Estado frente a este tema:

"Siempre se ha dicho que si todos los que han dirigido el país se hubieran preocupado un poquito más del progreso intelectual del pueblo, este no presentaría la lepra inmunda de los vicios que hoy lo domina casi por completo. Los señores oligarcas que nos han gobernado hace más de cien años, poco o nada se han preocupado de darle a la instrucción el verdadero desarrollo, para sustraer al pueblo ignorante de la oscuridad en que está sumido." El Despertar de los Trabajadores. Abril 1921. N 1966. En (Sandoval, 2012)

Con algunas semejanzas se aprecia la postura de El Socialista, que declara:

"La forma moderna de la organización obrera debe cimentarse sobre dos principios indispensables: El mejoramiento moral que aumente la intelijencia en forma, siempre progresiva como medio de conquistar todos los medios de felicidad. El mejoramiento material hasta llegar a un sistema perfecto de organización industrial, que suprimiendo la explotación y la opresión proporcione todos los medios de bienestar social universal." El Socialista, Agosto 1915. En (Brión, 2016)

Los medios escritos presentan una serie de objetivos en la difusión de los contenidos en sus páginas. En ellos destaca principalmente el conflicto de intereses con los grupos dominantes, aunque también la búsqueda de moralización de las clases populares. En este sentido, el periódico Mar y Tierra sostiene:

"Nuestra sociedad que ha sido el blanco de todas las injurias de parte de los logreros del trabajo ajeno, ha comprendido que el único medio de evitar el avance de esos audaces, es instruir a sus asociados, por lo que se ha fundado una Escuela Nocturna que cuenta con un personal de profesores, todos hijos del trabajo y que sin el menos interes de lucro, vienen gustosos a enseñar a sus hermanos el deber que le corresponde como hombres sociales y no sigan siendo víctimas de la esplotacion inicua que le hacen los que hasta hoy tienen monopolizado los trabajos marítimos, violando las tarifas de salarios, que como ley existen en la Gobernacion Maritima de este Puerto." Mar y Tierra, 12 de Marzo de 1911: 3. En (Brión, 2016)

Por un rumbo semejante se observan los objetivos de La Hoja Popular que declara:

"Se ha anunciado para dentro de poco la inauguración de un centro de conferencias públicas, con programa popular, cuyo centro sería por ahora el gran salón de El Mercurio. Desde estas columnas destinadas al pueblo. La conferencia es hoy por hoy la mejor propaganda que existe. El libro es caro y pesado de leer para el hombre de poca cultura y de mucha labor; el diario no cuenta con espacio suficiente para las materias ampliamente científicas o literarias; la cátedra está cerrada para el hombre de escasos recursos. Solamente la conferencia es un medio adecuado para instruir 
con deleite, para inculcar enseñanzas beneficiosas en lenguaje que esté al alcance de todo el mundo." La Hoja Popular, Diciembre de 1911, N5 :4. En (Brión, 2016)

Una opinión diferente se aprecia en El Socialista, que declara como objetivo la moralización de las clases populares:

"Deberíamos esforzarnos por elaborar un programa, un curso sencillo y práctico sobre el alcoholismo, sus causas, sus formas y efectos, al alcance de los maestros, que estos deberían conocer necesariamente y que podrían ellos, tan espléndidamente, inculcar a sus pequeños discípulos. Es conocido, por un lado, el inmenso y merecido prestigio que tiene el maestro entre sus discípulos y también en las familias, y por otro lado, la edad favorable para esta enseñanza, que representa la niñez, cosas ambas que harian grandemente fecunda la enseñanza del maestro de escuelas. El niño, y a su vez, fuerte en su convicción y fuerte en la convicción representaría por la palabra del maestro, seria, no sólo un creyente convencido y, por consiguiente." El Socialista, 8 Marzo 1917. En (Brión, 2016)

En la misma línea que el periódico anterior, El Despertar de los Trabajadores hace hincapié en la importancia de la educación popular para prevenir y eliminar los vicios asociados a la vida obrera, como se puede observar a continuación:

"perder el tiempo en las cantinas, garitos y burdeles que sólo traen la corrupción, la degeneración y la cobardía de los individuos. Con estos vicios los obreros son incapaces de luchar para poder en el futuro gozar de una vida feliz, más desahogada; sólo serán esclavos toda su vida, sólo serán serviles del capital, porque nunca piensan estudiar, en prepararse para la vida social." El Despertar de los Trabajadores, 10 de Agosto 1921. N²077. En (Sandoval, 2012)

Los medios también disponen de una propuesta curricular para educar a las clases populares en Chile. Estas propuestas varían desde las asignaturas que deben servir de fundamento a la enseñanza del mundo trabajador, hasta la formación cívica y ciudadana de esta población. En este sentido, el periódico Mar y Tierra propone:

"A esta Escuela pueden ingresar todos los trabajadores que lo soliciten a la Sociedad pudiendo pasar a matricularse en el rejistro de la Escuela desde el 15 del presente mes. Las clases principiarán desde el $1^{\circ}$ de Abril; las horas de estudio serán de 7 PM a 9 PM. Todos los días de trabajo, a escepcion del dia jueves que serán destinado a conferencias sobre historia Social de los países Europeos y Americanos, como también se desarrollaran temas instructivos sobre Moral, Hijiene, Ciencias y Sociolojia etc. La Escuela Nocturna está ubicada en el salón social Blanco 54 y Av. Errazuriz 32." Mar y Tierra, 12 de Marzo de 1911: 3. En (Brión, 2016)

Con semejanzas y diferencias La Hoja Popular propone:

"Los conocimientos que va adquiriendo, necesariamente lo estimulan para perfeccionarse en su oficio y aprender la parte teórica de este. Así es como vemos carpinteros que se transforman en arquitectos, y obreros que llegan a ser buenos ingenieros mecánicos. Ejemplos de esto ultimo se pueden observar en las marinas nacional y estranjeras." La Hoja Popular, Noviembre 1912, № 11. En (Brión, 2016) 
Con un sello cívico encontramos la propuesta de El Socialista:

"La escuela debe ser para nosotros nuestra casa, nuestro anhelo, puesto que en ella aprenderemos, y también nuestros hijos, a ser ciudadanos conscientes de nuestros deberes, debemos nosotros hacer un esfuerzo para proporcionárnosla, uniéndonos todos y aunando nuestros medios fundemos escuelas nocturnas para instruirnos nosotros y nuestros hijos, en una palabra todos, hombres, mujeres y niños." El Socialista, 14 de Agosto de 1915. En (Brión, 2016)

Realizando un diagnóstico lapidario desde la perspectiva de la formación de los ciudadanos, El Despertar de los Trabajadores plantea que:

"Es una vergüenza para el país mantener en una situación deprimente a una clase que es la moldeadora de las sociedades, a un cuerpo de ciudadanos sobre los cuales descansa la prosperidad y grandeza de la nación" El Despertar de los Trabajadores, 4 de Abril 1922. N²270. En (Sandoval, 2012)

Una de las principales características de esta prensa es que presenta atributos propios tanto del modelo doctrinario de prensa, como del modelo informativo de los medios de comunicación. En este sentido, los periódicos nos informan de textos escritos de difícil clasificación. Hablamos de prensa que presenta descriptores propios tanto del periodismo empresa, como de los tradicionales periódicos doctrinales hijos de la revolución francesa. Es posible que producto de estas características, registremos en la opinión de esta prensa atributos ideológicos más complejos que los observables en los periódicos nacionales del siglo XIX.

En el terreno estricto de la opinión de esta prensa en el plano de la educación del mundo obrero, los periódicos presentan una serie de discursos escritos con claras declaraciones de principios. De estos destacan los razonamientos que vinculan la ignorancia del mundo popular con la mejora de su condición material y espiritual. La falta de conciencia de las clases populares en torno a su precariedad y a la necesidad de su moralización y organización para su mejora social, son tópicos discursivos que se aprecian de manera evidente en esta prensa.

Otro aspecto observable en esta opinión es la presencia de discursos centrados en los objetivos de difusión en esta prensa. En estos se aprecian tópicos tales como el conflicto de intereses intergrupal, más la necesidad de educar a las clases populares para la toma de conciencia de esta situación, tal como lo plantea El Despertar de los Trabajadores. Otro tópico discursivo presente está ligado explícitamente a los métodos de instrucción. En este sentido, periódicos como La Hoja Popular presentan una opinión diagnóstica sobre las estrategias didácticas para la enseñanza del mundo popular, ligadas a lo que él llama la conferencia. Un tercer observable en estos escritos está ligado a la necesidad de moralizar al mundo del trabajo. En este sentido, opiniones como los del periódico El Socialista ligados a lo que esta opinión llama la elaboración de un programa, más el papel del maestro en el proceso de moralización, constituye un tópico discursivo presente.

Por último, la opinión de esta prensa da cuenta de una propuesta curricular pensada para educar a las clases populares de Chile. Las propuestas oscilan desde las asignaturas 
fundamentales para esta enseñanza, hasta la necesidad de la formación cívica y ciudadana de esta población. En las próximas líneas observaremos los principales disensos de esta prensa en el terreno de la instrucción, ligados a la educación de la mujer.

\section{La educación de la mujer}

La prensa escrita del período presenta opiniones disímiles a la hora de abordar la educación de la mujer popular. En este sentido, resulta evidente la fractura ideológica de los medios de corte anarquista de los que se inclinan más por una orientación socialista. De esta manera, en el terreno del abordaje del papel de la mujer en la sociedad de su tiempo, el periódico Verba Roja declara:

"Los frailes capataces del Cristo mitilójico fueron a votar en un concilio sobre si la mujer tenía alma o no. Si las almas son lo que valen para ellos - como que inventaron el negocio de salvarlas - ¿Qué valía para ellos la mujer si no tenía alma? ¡Por eso la llaman "carne de pecado"! Los gobiernos, que son relijiones nuevas, tienen en las prisiones celdas especiales para la mujer pobre." Verba Roja, 1923: 4. En (Palma y Pinto, 2015)

Por un rumbo semejante opina El Martillo de Antofagasta, cuando sostiene:

"Nosotras las mujeres, somos esclavas desde antes que hubieran esclavos; pero hoy somos de la Relijión, del Capital y del Matrimonio. Mañana seremos libres, porque vamos dándonos cuenta del inícuo rol que desempeñamos en la horrorosa comedia humana; (Sociedad) vamos ya iniciándonos en el grandio o movimiento social. Ya alzamos nuestra voz para reclamar nuestros lejítimos derechos, nunca tenidos en cuenta y eternamente desconocidos por los usurpadores," (iSanguijuelas del proletariado!) El Martillo de Antofagasta, 1914: 4-5. En (Palma y Pinto, 2015)

Una opinión diferente se observa en La Hoja Popular, donde se aprecia una postura bastante más tradicional en torno al rol femenino en sociedad:

"La mujer vivirá para su esposo, hijos, su casa; para alimentarse y materialmente; será la sincera consejera de su esposo en las grandes luchas de la vida, modesta, prudente, obediente, buena amiga; hará el bien donde pueda y servirá de ejemplo a sus hijos y al medio social donde vive." La Hoja Popular, Octubre 1913. º 20. En (Brión, 2016)

Siguiendo esta visión tradicional, observamos en El Despertar de los Trabajadores una postura sobre la "debilidad" intelectual de las mujeres a la que hay que hacerle frente:

"La mujer instruida, educada convenientemente, comprendería lo bueno y lo malo, respetaría lo que fuera digno y odiaría todo lo corrompido que tiene el mundo, sabría lo que son vicios y lo que son virtudes" El Despertar de los Trabajadores, 12 de Diciembre 1912. N 161. En (Sandoval, 2012)

En este terreno se observa una marcada diferencia de opinión en torno a la mujer y su papel en sociedad. En este sentido, mientras los medios anarquistas abordan la necesidad de emancipación femenina en una sociedad estratificada, el tercer medio 
considerado en este artículo desestima esto en una sociedad igualitaria. De esta manera Verba Roja sostiene:

"La libertad de la mujer no vendrá, pues, de arriba. Llegará con una revolución completa, que no será otra que la anárquica. Son armas inútiles los partidos políticos femeninos, y peor si son cívicos. Los socialistas, además, socializarán a la mujer, la harán un objeto del Estado." Verba Roja. primera quincena de 1923: 4. En (Palma y Pinto, 2015)

Con algunas semejanzas se observa la opinión de El Martillo de Antofagasta, que sostiene:

"La mujer dentro del matrimonio, estaba considerada como un "objeto de placer, como máquina de hacer hijos o esclava doméstica", no podían manifestar sus gustos ni opiniones, frente a esta esclavitud, la mujer debía emanciparse, se llamaba a que las trabajadoras y mujeres feministas y anarquistas tenían la "misión de formar hombres libres, de iniciativa y de gran impulso intelectual" El Martillo de Antofagasta, 1914: 4-5. En (Palma y Pinto, 2015)

Una opinión muy diferente se aprecia en La Hoja Popular, que le asigna un papel subalterno a la mujer frente al hombre:

"Se debía educar a una mujer de casa, fuerte de alma y espíritu y así: "Pueda retener a su compañero con su amable ternura y las ventajas del hogar limpio y estable, apartándolo de la taberna y el vicio que tantos organismos destruye y tantos espíritus pervierte." La Hoja Popular, Diciembre 1914. En (Brión, 2016)

De hecho, en El Despertar de los Trabajadores, se entiende la instrucción de la mujer también como la formación en sus labores maritales y domésticas:

"Criada desde pequeña lejos del contacto del hombre, acostumbrada a mirar a este no como al compañero de su vida, sino como a un enemigo peligroso, a quien hay que temerle, forman en ella un espíritu lleno de prejuicios ridículos en sus primeros años, que desaparecen después, cuando en sociedad se ve seducida por sus galanterías... Cuando después de haber vivido una época de su vida rodeada de un ambiente tan falso como perjudicial, contrae matrimonio, se encuentra que la vida del hogar no es el paraíso que ella se forjó en sus ilusiones celestes" El Despertar de los Trabajadores, 28 de Enero 1921. № 1911. En (Sandoval, 2012)

Las diferencias de óptica de estos medios en torno al papel de la mujer en la sociedad, se traduce en la propuesta educativa hacia la población femenina. Con perspectiva crítica, Verba Roja sostiene en relación a la dicotomía hombre/mujer:

"mientras ellos activan, discuten y estudian buscando los medios que les permitan llegar más fácilmente a las masas iluminando sus cerebros para desterrar de ellos los diferentes prejuicios que le impiden conocer sus derechos y deberes, la mujer está dando a la sociedad nuevos seres emprejuiciados, abyectos, una nueva generación de esclavos, policiales, carceleros y soldados, que son fuerza y sostén de 
todos los gobiernos autoritarios y criminales." Verba Roja, primera quincena 1923: 3. En (Palma y Pinto, 2015)

Profundizando en esta perspectiva crítica sobre la mujer, en El Despertar de los Trabajadores encontramos una postura específica hacia las maestras:

"El profesorado femenino es instrumento ciego del Vicario y con obediencia igual cumple los mandados de este con mayor exactitud que si fueran órdenes de la visitación" El Despertar de los Trabajadores, 24 de Diciembre 1912. N 165. En (Sandoval, 2012)

Con una perspectiva más optimista El Martillo de Antofagasta opina que se debe educar a la mujer, porque "por su naturaleza es maestra y guía de la infancia; emancipémosla de todos los prejuicios, para que señale a sus hijos la iluminada senda de la Libertad". El Martillo de Antofagasta, enero de 1914: 2-3. En (Palma y Pinto, 2015)

\section{Verba Roja:}

Una opinión más tradicional se observa en La Hoja Popular, en claro contraste con

“Debemos formar a la mujer proletaria, educada trabajadora y modesta: preparada para la función de la maternidad digna y abnegada, que sepa cuidar la preciosa existencia de sus pequeñuelos criándolos de cuerpo sano y espíritu fuerte." La Hoja Popular, Diciembre 1914. En (Brión, 2016)

En este tópico discursivo resulta más evidente la diferencia entre los medios consultados. Al profundizar los aspectos ligados a la educación de la mujer, se observan tres posturas que oscilan desde el abierto igualitarismo, hasta modelos más tradicionales sobre la educación femenina. En este sentido El Martillo de Antofagasta sostiene que, más que tratar a la mujer como esposa, hija o hermana, se le debe tratar:

“...como compañera, como parte más sensible de nuestro organismo, como a nuestra misma existencia en peligro. Llevémosla a todas las partes donde pueda adquirir una sana enseñanza; alimentemos su cerebro con todos los buenos y bellos conocimientos que hayamos adquirido de la Ciencia Social, y veremos, que en vez de la mujer que nos riñe por cualquier nimiedad, tendremos una amante y cariñosa compañera, que compartirá con nosotros las alegrías y las penas de la lucha y nos consolará en los ratos de desaliento. Procuremos que la educación de las niñas, esté en línea paralela a la de los niños y tendremos en vez de un obstáculo para el progreso, un admirable e intrépido auxiliar." El Martillo de Antofagasta, enero de 1914: 2-3. En (Palma y Pinto, 2015)

Con algunas diferencias Verba Roja presenta una opinión favorable a que las mujeres se acerquen a la instrucción libertaria y tomen distancia de las ideas de Dios y de Patria:

“El miedo a lo sobrenatural y la estrofa patriótica, hábilmente puesta en juego por educacionistas oficiales, extinguieron en mí todo raciocinio y así como la noche rogaba, transida de miedo para aplacar las cóleras divinas, los himnos y marchas patrióticas, me embriagaban haciéndome desear ser madre para brindar mis hijos a 
la grandeza de la patria. (...) iMadres! Seguid mi ejemplo: se os repite Dios y Patria, pues ni Dios ni Patria; porque ambos han sido inventados por tiranos para esclavizar a los pueblos; en cuanto a vuestros hijos, educadlos en la escuela racionalista para que mañana combatan por la revolución social." Verba Roja, primera quincena de junio 1919: 2. En (Palma y Pinto, 2015)

Una opinión bastante más tradicional se observa en La Hoja Popular, que propone que:

"Es necesario, pues, antes que nada, procurar la buena educación de la hija del pueblo: pero la educación propiamente dicha, no la acumulación de conocimientos intelectuales inútiles que no le dan aptitudes verdaderas y la envanecen haciéndola despreciar al trabajo y a sus compañeros." La Hoja Popular, Diciembre 1914. En (Brión, 2016)

Si bien los periódicos ácratas no difieren en su estructura en torno al modelo de prensa, si se diferencian en forma sustancial en la dimensión doctrinal sobre la educación de la mujer. En este sentido, la opinión de la prensa anarquista da cuenta de una búsqueda de la emancipación femenina mediante la educación que está ausente en los demás periódicos. Este hecho es evidente cuando los discursos ácratas hablan de la esclavitud de la mujer, o de la necesidad de una revolución completa para hombres y mujeres. Un aspecto relevante de la opinión anarquista es la abierta distancia ideológica que toman frente a otros movimientos sociopolíticos, tales como los partidos políticos femeninos o los de carácter cívico, por considerarlos armas inútiles. Una situación semejante se observa con el socialismo, criticando la objetivación de la mujer por parte del Estado.

Frente a esta opinión contrasta el discurso de La Hoja Popular y El Despertar de los Trabajadores, que presentan un proyecto educacional más próximo a valores tradicionales. Al entender a la mujer en su relación con la familia, en calidad de esposa y madre, muestra un razonamiento más propio de la cultura tradicional, opinión que podría tener alguna inspiración de matriz rural. Tópicos discursivos en torno a la mujer, tales como la necesidad de ser consejera de su esposo, modesta, prudente, obediente o buena amiga, nos informan de una opinión más propia de las colectividades rurales que de discursos intelectuales, urbanos y cosmopolitas. Es posible que esta divergencia doctrinal explique la agenda temática de estos medios y su objeto pedagógico de interés. También puede relacionarse con que los periódicos de orientación socialista o, en general, más tradicional, se apeguen ideológicamente a las instituciones establecidas como el Estado, la Nación o la familia, dada su valoración del Estado como medio de obtención del poder, tal y como puede observarse en el análisis de El Despertar de los Trabajadores (Sandoval, 2012)

Como veremos en las siguientes líneas, la prensa obrera con credenciales no ácratas presentan una profunda preocupación por la infancia y su educación. 


\section{La educación de la infancia}

La prensa obrera del período presenta una serie de opiniones sobre la educación de la infancia, donde destacan más las similitudes que las diferencias. En este terreno, los diagnósticos sobre la situación social de niñas y niños y las dificultades para acceder a la instrucción son los principales tópicos presentes en sus percepciones.

Tanto La Defensa Obrera, como La Hoja Popular y El Socialista coinciden en el diagnóstico sobre la situación social de la infancia popular, ligada al mundo del trabajo asalariado. En este sentido, La Defensa Obrera sostiene:

"Fuimos, hace poco a un establecimiento maderero de Valparaíso, i recorriendo todo su interior, entre los operarios había un pequeñito que por su estatura i facciones del tipo no tendría mas de ocho años de edad i trabajaba brutalmente. Frente a él nos detuvimos a contemplarlo como, con grandes sacrificios de sus debilísimos musculitos en incipiente desarrollo, tiraba con sus manesitas las estremidades de las tablas que salían de las máquinas elaboradoras. El, el pobresito, el pequeño trabajador se ponia rojo en la tarea." La Defensa Obrera, Sábado 27 de Junio de 1914. Numero 32. En (Brión, 2016)

El Despertar de los Trabajadores establece la necesidad de educar a los niños tanto en el conocimiento teórico como en las habilidades profesionales que puedan ejercer en el futuro:

"Como la escuela única tiene por base la educación social, no hará del niño ni un futuro sabio ni un apéndice de la máquina. Su tarea es despertar todas las capacidades del niño, desarrollar sus fuerzas productoras y educarle de modo de que como miembro de una sociedad comunista 'trabaje como campesino y piense como filosofo'" El Despertar de los Trabajadores, 25 de Julio 1923. $N^{\circ}$ ilegible. En (Sandoval, 2012)

Un diagnóstico similar se observa en la opinión de El Socialista, destacando la disponibilidad del sistema escolar para impartir instrucción a los niños:

“Desde la semana pasada está lista la matrícula en las escuelas publicas para recibir las inscripciones de las niños que deben concurrir a esos establecimientos para recibir la instrucción a que tienen derecho como ciudadanos de un país. Año por año en esta misma época, se abre la campaña en los diarios a estimular la asistencia de niños a los establecimientos de instrucción primaria del Estado, con objeto de estimular a los padres de familia al cumplimiento de sus deberes. Los maestros por otra parte, hacen la propaganda con el mismo objeto, sin ahorrar modestias y golpeando de puerta en puerta los hogares, predicando para que los padres envíen sus hijos a la escuela y no los dejen sin instrucción." El Socialista, 23 de Marzo 1918. En (Brión, 2016)

Con importantes similitudes a las opiniones anteriores, La Hoja Popular crítica el comportamiento de los padres al no enviar a sus hijos a la escuela: 
"Los padres que descuidan la educación de sus hijos, son responsables ante la sociedad, a quien interesa una buena educacion, de la falta de cumplimiento de uno de los deberes mas sagrados del hombre, haciéndose merecedores de una sanción social." La Hoja Popular, Octubre 1912. N¹1. En (Brión, 2016)

De la misma forma, El Despertar de los Trabajadores hace hincapié en la responsabilidad de los padres sobre el trabajo infantil y la educación de los niños:

"Instruyendo al niño de hoy, habremos formado al hombre de mañana y salvando a la patria de una gran hecatombe... No sabe el padre que mal hace aprovechándose de los servicios domésticos de su hijo para alimentar la familia y dejándose en la ignorancia" El Despertar de los Trabajadores, 28 de Marzo 1916. N925. En (Sandoval, 2012)

Los medios coinciden en el valor que tiene la instrucción para el presente y futuro de la infancia en Chile. En este sentido, la opinión más crítica hacia el comportamiento de los padres al no enviar a sus hijos a la escuela se observa en La Defensa Obrera, quien sostiene:

"Si los trabajadores chilenos hubieren comprendido en otros tiempos que ellos mismos debieran hacer las leyes que prohíben el trabajo a niños y que, forzosamente deben ir a las escuelas antes que a la fábrica, ya estaríamos imitando a Suiza, Francia, Alemania, Inglaterra, Estados Unidos, etc. Allá han sido los representantes obreros los reglamentadores de la jornada i de la instrucción forzosa. Aquí la apatía de los trabajadores ante el problema social, ha dejado dominar a la oligarquía i ahí tenemos el asesinato de la vida de los niños en las fábricas por la indiferencia de los proletarios." La Defensa Obrera, Sábado 27 de Junio de 1914. Numero 32. En (Brión, 2016)

Una opinión similar se observa en El Socialista, que nuevamente critica el comportamiento paterno en torno a la instrucción de sus hijos:

“Desgraciadamente, no todos los padres de familia se dan cuenta de los deberes que les corresponden con respecto a la educación, dejándolos entregados a la ignorancia más completa. De ahí nace la vagancia y la mendicidad de los niños, los vicios y toda clase de males que aquejan a la infancia y que lleva mas tarde a los individuos a las cárceles o a los manicomios. La ley se ha puesto en el caso de los padres que desatienden sus deberes para con sus hijos en lo tocante a la educación y establecen severa sanción para castigar a los que indolentemente permiten que sus hijos no vayan a las escuelas y los abandonen a la vagancia." El Socialista, 23 de Marzo 1918. En (Brión, 2016)

Una perspectiva fundada más en el aprendizaje de los niños se observa en La Hoja Popular, dando cuenta del manejo de una opinión pedagógica en su análisis:

"El niño del hoi es el hombre del mañana y es a éste a quien debemos educar física y moralmente. FÍSICAMENTE se hace por medio de juegos al aire libre y los sports. MORALMENTE sacándolos de los centros de corrupción o de aquellos sitios en cuyo 
ambiente se aspira la atmósfera que mas tarde les será perniciosa." La Hoja Popular, Junio 1914. En (Brión, 2016)

La importancia de la educación en la infancia, y del juego como método principal de esta también aparece mencionada en El Despertar de los Trabajadores:

"Vulgarmente se cree, dice F. Climent, que los niños pierden el tiempo jugando en vez de aprender lecciones de memoria. No tienen en cuenta quienes tal creen, que el juego debe ser una 'asignatura de enseñanza', mucho más provechosa que el piano, dibujo y demás clases impropiamente llamadas de adorno; tan importante es el juego como pueden serlo la gramática o la aritmética" El Despertar de los Trabajadores, 15 de Junio 1916. N 992. En (Sandoval, 2012)

De los periódicos consultados, solo dos se pronuncian en torno a las falencias de la instrucción de la infancia en Chile. En este terreno La Defensa Obrera opina que "Los niños pobres no reciben la instrucción necesaria cuando analfabetos, porque a sus pares les faltan: los medios para enviarlos a la escuela, templo donde se disminuye la ignorancia en los primeros pasos que dan las jeneraciones infantiles." La Defensa Obrera, Sábado 28 de Febrero 1914. N¹6. En (Brión, 2016)

Una opinión semejante se observa en La Hoja Popular, al sostener que "La población de nuestros colejios es al presente de constitución débil y enfermiza; se manifiesta rebelde e indiferente a los consejos del profesor y, en muchísimos casos, irrespetuosa e insolente. No tiene apego a los libros y si, marcada tendencia al libertinaje." La Hoja Popular, Septiembre 1915. En (Brión, 2016)

De la prensa consultada, destaca La Hoja Popular y El Despertar de los Trabajadores al ser los únicos medios que presentan una propuesta de modelo pedagógico, frente al complejo escenario social de la infancia popular en Chile:

"La niñez es la libertad. Aun es un delito la enseñanza severa. Solo una escuela es buena, ha dicho Pestalozzi: aquella que imita y se parece a la madre." La sociedad moderna debe hacer mas, debe ir a los niños, llevarles en toda ocasión alimento y cultura, no esperar que ellos se acerquen a la demacración en el rostro y la tristeza en el corazón. "Los niños son intelijentes hasta que el padre o el maestro toman a su cargo la tarea de embrutecerles." La Hoja Popular, Septiembre 1913, № 19. En (Brión, 2016)

En el caso de El Despertar de los Trabajadores, este adscribe a las ideas de la Escuela Racionalista de Francisco Ferrer Guardia, español que planteó la necesidad de educar a la infancia en las ciencias, artes, industria, etc, pero a la vez, formarlo en la consciencia social para convertirlos en seres humanos completos (Sandoval, 2012)

En esta opinión La Hoja Popular da cuenta de un dominio teórico sobre ciertas pedagogías sensualistas y terapéuticas para afrontar contextos sociales precarios en el terreno material y simbólico. De hecho, es evidente su defensa por una instrucción de carácter laica: 
"Si un padre quiere formar de su hijo un Tartufo lo educa conforme a las doctrinas de los que sostienen un misticismo irracional, ideado para esplotar a la sociedad; pero si aspiran a formar un hombre de bien, un buen ciudadano, debe procurar inculcarle los preceptos de la moral pura y jamas impresionarlos con relatos mitolójicos." La Hoja Popular, Octubre 1912. №11. En (Brión, 2016)

Para El Despertar de los Trabajadores, la educación laica era de igual importancia para la educación obrera:

"Las escuelas dirigidas por el clero y sustentadas con el presupuesto fiscal, no son los planteles de educación que preparan al hombre o a la mujer para pensar libremente. En esas escuelas, a más de imponérseles a los educandos una falsa enseñanza, inventada por la teocracia religiosa, se les pretende tener sumidos en la ignorancia a fin de que no puedan investigar más allá de la doctrina cristiana" El Despertar de los Trabajadores, 9 de Diciembre 1914. N 521. En (Sandoval, 2012)

Llama la atención el contraste entre este periódico y el resto de la prensa obrera. Como observamos en páginas anteriores, los periódicos consultados no difieren fundamentalmente en calidad de modelos de prensa. Sin embargo, en el terreno de la opinión presentan diferencias doctrinales marcadas en relación a la agenda temática de cada medio. Si bien los periódicos coinciden en el diagnóstico sobre la infancia popular en Chile y el horror de su condición en calidad de trabajadores asalariados, difieren en el terreno de su propuesta pedagógica. En este sentido, La Hoja Popular dispone tanto de un sofisticado diagnóstico sobre el estado de la enseñanza de la infancia, como de un elaborado modelo educacional. De esta manera, al identificar problemáticas tales como la constitución débil y enfermiza de los niños, o el espíritu rebelde e indiferente frente a los consejos del profesor, da cuenta de esta capacidad.

Un aspecto que destaca de esta opinión es el manejo de un modelo pedagógico para la enseñanza de la infancia popular en Chile. Al sostener que la niñez es libertad, o mencionar la figura de Pestalozzi y su propuesta educacional, nos informa de un medio de comunicación que propone de una didáctica útil para la educación popular. La explícita toma de distancia con lo que llama misticismo irracional, en abierta alusión a la instrucción religiosa, da cuenta de una opinión racionalista en torno al proyecto educativo de la infancia popular en Chile, al igual que El Despertar de los Trabajadores, que propuso establecer la Escuela Racionalista y metodologías científicas en la educación dirigida al obrero.

\section{CONCLUSIONES}

El análisis de la prensa obrera en torno a la educación popular del período en Chile, da cuenta tanto de semejanzas como de diferencias en calidad de medios de comunicación escrita. Las principales similitudes se observan en el plano del modelo de prensa a la que tributan, a medio camino entre el esquema doctrinario y el modelo informativo. En este sentido, los periódicos presentan atributos estructurales semejantes que nos proporcionan una primera aproximación al análisis de nuestro objeto.

Otro aspecto semejante se observa en la preocupación por el bienestar del mundo popular y los principales problemas que lo aquejan. La falta de instrucción, las creencias 
irracionales y los grupos sociales dominantes constituyen los principales desafíos a enfrentar. La necesidad de una educación racional, moralizadora y concientizadora constituyen tópicos comunes en los discursos de esta prensa.

Los principales disensos en la opinión de la prensa obrera se observan en el terreno de la educación de la mujer. Los periódicos ácratas se distinguen del resto por una defensa de la emancipación de esta de los roles sociales tradicionales, ligadas a su condición de madre y esposa. En este sentido, la prensa anarquista entiende la educación como un instrumento de redención, en la cual la mujer debe ser liberada de los factores sociales que la constriñen. Frente a esto, otros periódicos como La Hoja Popular defienden un modelo tradicional sobre el papel de la mujer en el mundo popular y su educación.

En el plano de la educación de la infancia popular, destacan medios como La Hoja Popular, debido a que dispone de un modelo pedagógico para la enseñanza de niños y niñas. El conocimiento de la obra de Pestalozzi y el manejo que hacen de su propuesta teórica, nos informan de un periódico que propone de una didáctica útil para la educación popular. Con un claro discurso racionalista, este medio da cuenta de una opinión que dispone de un plan de trabajo terapéutico para educandos en una precaria situación material y afectiva. También destaca El Despertar de los Trabajadores, donde no sólo se establece un tipo de escuela en particular como la más apta para la educación popular, sino que también muestra conocimiento sobre los mejores métodos de enseñanza para la infancia y la necesidad de erradicar el trabajo infantil para que puedan dedicar todo su tiempo a su educación y formación profesional.

Los principales alcances de este trabajo se observan en el terreno de estudiar a los individuos que ofician como periodistas en estos medios. Conocer la biografía o los orígenes culturales y educacionales de estos sujetos, nos informarían sobre el por qué de numerosas opiniones ligadas sobre todo al disenso presentado sobre la educación de la mujer. Un discurso obrerista que defiende roles tradicionales sobre la población femenina, podrían ser consecuencia de numerosos factores que escapan a la presente investigación. Será deber de futuros estudios hacerse cargo de esta tarea.

\section{BIBLIOGRAFÍA}

Arias, O. (1970) La prensa obrera en Chile 1900-1930. Chillán: Universidad de Chile.

Aedo-Richmond, R. (2000) La educación privada en Chile: Un estudio histórico- analítico desde el período colonial hasta 1990. Santiago: RIL Editores.

Barría Serón, J. (1971) El movimiento obrero en Chile: Síntesis histórico-social. Santiago: Trígono.

Egaña, L; Nuñez, I; Salinas, C. (2003) La educación primaria en Chile: 1860-1930. Santiago: LOM.

Brión, C. (2016) illumina tu razón en el estudio para la lucha social! Demandas, ideales y propuestas educativas del movimiento obrero en Valparaíso, 1910-1920. Tesis para optar al grado académico de Licenciado en Historia y Ciencias Sociales y Licenciado en Educación. Valparaíso: Universidad de Valparaíso. 
Egaña, L; Monsalve, M. (2006) Civilizar y moralizar en la escuela primaria popular. En: Sagredo, R. y C. Gazmuri. Historia de la vida privada en Chile. Tomo II. El Chile moderno de 1840-1925. Santiago: Editorial Taurus.

Figueroa, C; Silva, B. (2006) Entre el caos y el olvido: la acción docente en la provincia de Tarapacá-Chile (1880-1930). Cuadernos Interculturales 4(6): 37-53.

Figueroa, C; Silva, B. (2011) La demanda política de un actor educativo: El visitador de escuelas primarias Ramón López Pinto (Tarapacá, Norte de Chile 1889-1907). Cuadernos de Historia 34: 53-81.

González, J. (2002) El impacto de la guerra del Paraguay en la opinión de la prensa de Chile central: notas para una exploración (1864-1870). Estudios Trasandinos 7: 235-254.

González, S. (2002) Chilenizando a Tunupa. La escuela pública en el Tarapacá andino 18801990. Santiago: DIBAM.

Habermas, J. (1981) Historia y crítica de la opinión pública. Barcelona: Gustavo Gili.

Illanes, M.A. (1990) Ausente, señorita. El niño chileno, la escuela para pobres y el auxilio. Chile, 1890-1990. Santiago: JUNAEB.

Moulián, T. (1987) Concepción de la política e ideal moral en la prensa obrera 1912-1922. Santiago: FLACSO.

Núñez, I. (1986) Gremios del magisterio. Setenta años de historia: 1900-1970. Santiago: PIIE.

Núñez, I. (2003) La ENU entre dos siglos. Ensayo sobre la Escuela Nacional Unificada. Santiago: LOM.

Ossandón, C. (1996) Modos de validación del texto periodístico de mediados del siglo XIX en Chile. Santiago: Centro de Investigaciones Sociales de la Universidad ARCIS.

Peñafiel, O; Zapata, M. (1994) Visión sobre el conflicto de la guerra de la Triple Alianza a través de la prensa de Santiago 1864-1870. Informe de Seminario para optar Grado Académico de Licenciado en Humanidades con mención en Historia. Santiago: Universidad de Chile.

Palma, N; Pinto, F. (2015) Educación anarquista en Chile. Propuestas y críticas educativas libertarias desde su prensa, 1903-1927. Tesis para optar al Grado Académico de Licenciado en Historia y Ciencias Sociales y Licenciado en Educación. Valparaíso: Universidad de Valparaíso.

Reyes, L. (2005) Movimientos educadores y construcción de política educacional en Chile (1921-1932 y 1977-1994). Santiago: Universidad de Chile.

Salazar, G. (1987) Educación popular y movimientos sociales en Chile. Blog post: http://es.scribd.com/doc/59016193/Educacion-Popular-y-Movimientos-SocialesGabriel-Salazar

Santa Cruz, E. (1988) Análisis histórico del periodismo chileno. Santiago: Nuestra América Ediciones. 
Santa Cruz, E. (1996) Modelos y estrategias de la prensa escrita en procesos de modernización: Chile siglo XX. Santiago: Centro de Investigaciones Sociales de la Universidad ARCIS.

Silva, B. (2009) Registros sobre la infancia: una mirada desde la escuela primaria y sus actores (Tarapacá, Norte de Chile 1880-1922). Revista de Historia Social y de las Mentalidades 2(13): 1-19.

Silva, B. (2010) Prácticas pedagógicas norteamericanas: una visión desde un actor educativo regional. Tarapacá Chile 1914-1922. Revista Estudios Norteamérica 20.

Silva, B. (2013) El sistema de instrucción primaria de la provincia de Tarapacá: voces y registros desde agentes escolares. Tarapacá, Norte de Chile 1880-1920. En: S. González. El ciclo del salitre, sus otras historias. Santiago: RIL editores.

Sandoval, G. (2012) La emancipación del pueblo depende de la educación. El Despertar de los trabajadores como expresión de los ideales educativos del movimiento obrero. Iquique, 1912-1926. Tesis para optar al Grado Académico de Licenciado en Historia y Ciencias Sociales y Licenciado en Educación. Valparaíso: Universidad de Valparaíso.

Silva Castro, R. (1958) Prensa y periodismo en Chile: 1812-1956. Santiago: Universidad de Chile.

Serrano, S; Ponce, M; Rengifo, F. (2012) Historia de la educación en Chile (1810-2010). Santiago: Taurus.

Valdebenito, A. (1956) Historia del periodismo chileno. Santiago: Círculo de periodistas de Santiago y círculo de prensa de Valparaíso.

Van Kessel, J. (1989) La iglesia católica entre los Aymarás. Santiago: Rehue.

Van Kessel, J. (1992) Holocausto al progreso. Los Aymarás de Tarapacá. La Paz: HISBOL. 